It is time to start looking more deeply for common attributes of all the immortalizing genes. Do others, apart from large $T$ and $p 53$, interact with each other and proceed through a common pathway? That some sophistication in our outlook is needed is highlighted by the recent characterization of an Abelson virus-transformed cell line, L12, that does not express p 53 because its gene has been inactivated by insertion of a retrovirus-like sequence into its first intron $^{12}$. L12 cells grow continuously in culture but, unlike other Abelson virustransformed cells, will not give rise to lethal tumours in syngenic animals. Instead the tumours regress spontaneously despite reaching considerable size. When a functional $p 53$ gene is reintroduced into $\mathrm{L} 12$ cells, those cells which then express the gene are able to give rise to progressive and lethal tumours. So, in this system, the $p 53$ gene product seems to act as a tumour progression factor, whose effect is only really detectable in an in vivo assay. This should delight rather than mystify, because the existence of a battery of oncogenes of subtly different effects, gives us a better chance to simplify and categorize the apparent plethora of human neoplastic diseases.

1. Parada, L.F., Land, H., Weinberg, R.A., Wolf, D. \& Rotter, V. Nature 312, 649 (1984)

2. Eliyahu, D., Raz, A., Gruss, P., Givol, D. \& Oren, M. Nature 312, 646 (1984)

3. Jenkins, J.R., Rudge, K. \& Currie, G.A. Nature 312, 651 (1984).

4. Lane, D.P. \& Crawford, L.V. Nature 278, 261 (1979)

5. Sarnow, P., Ho, Y.S., Williams, J. \& Levine, A.J. Cell 28, 387 (1982).

6. Crawford, L.V., Pim, D.C., Gurney, E.G., Goodfellow P. \& Taylor-Papadimitrou, J. Proc. natn. Acad. Sci. U.S.A. 78, 41 (1981).

7. DeLeo, A.B., et al. Proc. natn. Acad. Sci. U.S.A. 76, 2420 (1979).

8. Mercer, W.E., Nelson, D., Deleo, A.B., Old, L.J. \& Baserga, R. Proc. natn. Acad. Sci. U.S.A. 79, 6309 (1982). 9. Ruley, H.E. Nature 304, 602 (1983).

10. Land, H., Parada, L.F. \& Weinberg, R.A. Nature 304, 596 (1983).

11. Colby, W.W. \& Shenk, T. Proc. natn. Acad. Sci. U.S.A 79, 5189 (1982)

12. Wolf, D., Harris, N. \& Rotter, V. Cell 38, 119 (1984)

D.P. Lane is in the Cancer Research Campaign Eukaryotic Genetics Research Group, Imperial College, London $S W 72 A Z, U K$.

\title{
Immunology
}

\section{Uses of chimaeric antibodies}

\section{from Alan Munro}

ANTIBODIES were discovered through their ability to neutralize bacterial toxins, and for almost one hundred years antitoxin sera from experimental animals have been used to save many lives. For a brief period, it seemed that serum therapy would solve numerous medical problems. But it was soon found that repeated injections of a supposedly innocuous 'foreign' antibody can lead to harmful hypersensitivity reactions. With the availability of monoclonal antibodies, many new applications of serum therapy (for example, see last week's Nature; Cobbold et al. 312, 548) would become well worth exploring if only hypersensitivity reactions could be avoided.

There are three ways to approach this problem. The first is to use monoclonal antibodies from the standard source hybridomas of rat or mouse cells - but to induce specific unresponsiveness to rodent immunoglobulin before or during therapy. The second approach is to use human monoclonal antibodies, produced either from human hybridomas or from EpsteinBarr virus-immortalized human B lymphocyte cell lines; despite considerable efforts, the success of this approach has been limited and there is no generalized way of obtaining human monoclonals antibodies of the right specificity. Finally, by using the techniques of genetic engineering, it may be possible to obtain antibodies in which the antigen-binding site is defined by sequences from a rodent monoclonal antibody of the right specificity whereas the rest of the molecule is as 'human' in structure as possible.
Papers by G.L. Boulianne, N. Hozumi and M.J. Shulman on page 643 of this issue of Nature and by S.L. Morrison et al. in Proc. natn. Acad. Sci. U.S.A. 81, 6851; 1984 are the first to describe functional chimaeric antibody molecules containing light chains and heavy chains, in which the whole of the variable regions of the chains are 'mouse' and the constant regions are 'human'. Possibly the human immune system will not recognize such chimaeric molecules as foreign, but there are good reasons to think that it will. In many cases it is possible to mount an immune response against antibody molecules themselves, even when the only antigenic determinants lie in the variable regions (take, for example, the heavy-chain variable region allotypes in rabbits). At least it may be easier to induce unresponsiveness to rodent variable regions when they are part of chimaeric antibodies. In that respect, it will be interesting to compare the rates of clearance of chimaeric molecules with those of the normal antibodies molecules of the host. Even if it proves possible to construct chimaeric antibodies with rodent hypervariable regions embedded in a human variable region framework, it is likely that they will be recognized by the human immune system - but the hope is that such chimaeras will be sufficiently 'self-like' to become integrated into the network of interacting idiotypes and antiidiotypes without sensitizing the host and so avoiding subsequent hypersensitivity reactions.

The construction of chimaeric antibodies has been made possible through the development, by a number of independent groups, of vector systems that allow the expression of antibody light-chain or heavy-chain genes in cells that have been transfected with them. Many laboratories have since initiated experiments in which cells are transfected with modified antibody genes. Earlier this year J. Sharon et al. (Nature 309, 364; 1984) reported the expression of a novel fragment of antibody consisting of a normal light chain $\left(\mathrm{V}_{x} \mathrm{C}_{x}\right)$ associated with a modified antibody chain made up of a heavy-chain variable region linked to a light-chain constant region $\left(\mathrm{V}_{\mathrm{H}} \mathrm{C}_{\chi}\right)$. This fragment binds antigen and is secreted from the transfected cells (showing that the Fc portion of antibody is not necessary for secretion).

The report by M.S. Neuberger, G.T. Williams and R.O. Fox on page 604 of this issue not only confirms that result but goes much further. It shows that the Fc portion of the antibody heavy chain can be replaced by a completely unrelated protein - the enzyme staphylococcal nuclease for example - to produce a bifunctional

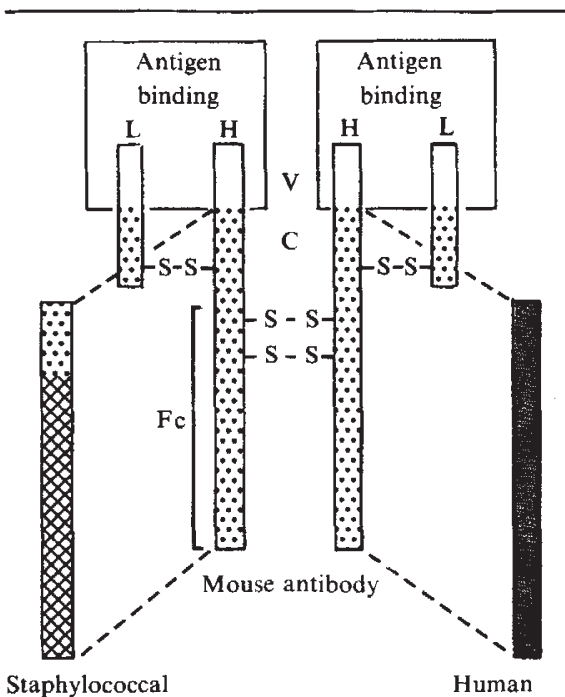

nuclease

constant region

Schematic diagram of a mouse antibody showing two identical light chains (L) and two identical heavy chains (H). Each chain consists of variable (V) and constant (C) domains. The antibody class is determined by the heavy-chain constant region which imparts distinctive features on the tail $(\mathrm{Fc})$ region. Neuberger et al. have substituted staphylococcal nuclease for the Fc region of both heavy chains of immunoglobulin M; Boulianne et al. have replaced the C domain of each heavy chain of the immunoglobulin $\mathrm{M}$ monomer with a human $\mathrm{C}$ domain.

chimaeric molecule - in this case, exhibiting both specific antigen-binding and nuclease activity. There are many potential applications of this technology in the purification of cloned gene products, in enzyme-linked immunoassays and in the targeting of chemotherapeutic drugs on to tumour cells.

Alan Munro is in the Department of Pathology University of Cambridge, Tennis Court Road, Cambridge CB2 1OP, UK. 